\title{
Multidisciplinary site investigations: refraction microtremor surveys
}

\author{
A. Pancha - R. A. Apperley
}

Received: 11 January 2021 / Accepted: 24 May 2021 / Published online: 11 June 2021

C) The Author(s) 2021, corrected publication 2022

\begin{abstract}
We present three case studies from recent site investigations that have utilised geophysical data to supplement traditional geotechnical investigations. The refraction microtremor (ReMi) method, which measures the shear-wave velocity of the subsurface soil profile, is used to enhance our overall understanding of geotechnical site conditions. Interpolation of the closely spaced one-dimensional velocity-depth profiles along linear arrays allows two- or three-dimensional velocity-versusdepth representations to be produced, thereby mapping lateral variations and extending subsurface characterisations between more expensive spot borehole measurements. The ReMi technique provides a noninvasive and cost-effective way of estimating vertical soil/rock shear-wave versus depth profiles and therefore is an effective reconnaissance tool for targeting key areas for further, more expensive intrusive investigation method. This paper examines the contribution ReMi shear-wave velocity assessments can make towards enhancing subsurface geological and geotechnical models
\end{abstract}

Article highlights $\cdot$ The refraction microtremor method extends subsurface characterisation between point geotechnical investigations.

- Mitigates construction risk by identifying anomalous unforeseen ground conditions between geotechnical investigations.

- Provides reconnaissance for intrusive investigations where complexity is observed.

\section{A. Pancha $(\bowtie) \cdot$ R. A. Apperley}

Aurecon New Zealand Limited, Wellington, New Zealand

e-mail: Aasha.Pancha@aurecongroup.com

R. A. Apperley

e-mail: Richard.Apperley@aurecongroup.com to mitigate risk from unforeseen ground conditions. Case studies demonstrate the benefits of incorporating the shear-wave velocity estimates from ReMi into the geotechnical investigations. These include identifying the thickness of basalt flows, identifying the location of buried stream channels, characterising palaeotopographical features, identifying areas of low velocity which may be prone to liquefaction, and assessing the thickness and velocity variations within geological units between borehole and test pit locations. The objective is not to replace traditional geotechnical investigations but allow more meaningful ground models to be developed.

Keywords COSMOS guidelines · Geotechnical shear velocity $\cdot$ Surface-wave dispersion $\cdot$ Refraction microtremor $\cdot$ Geotechnical ground conditions

\section{Introduction}

Refraction microtremor (ReMi) is a non-intrusive geophysical technique which uses ambient vibrations (background noise) generated by anything from vehicle traffic to the wind blowing nearby trees, to determine the underlying sub-surface shear-wave velocity structure. The method involves the deployment of a linear array of instruments to record ground motion generated by these ambient signals. This differs from other, similar, geophysical techniques that utilise active sources, requiring background noise to be at a minimum. Noisy urban environments provide an ideal setting for the 
ReMi technique, providing a fast and often costbeneficial method for obtaining sub-surface information. Developed by Louie (2001), the ReMi method has widely been used to determine shear wave velocity profiles and is used extensively to characterise sites for both engineering investigations and site response evaluations (e.g. Rucker 2003; Pullammanappallil 2006; Coccia et al. 2010). The ReMi technology was initially developed by Louie (2001) as a non-invasive surfaceperformed geophysical survey technique, to rapidly and cost-effectively measure the average shear-wave velocity to $30-\mathrm{m}$ depth to meet US building code requirements but has since been further developed towards comprehensive engineering applications. ReMi has been widely used for engineering applications to image very shallow sub-surface material structure in the upper 10 to $100 \mathrm{~m}$, as well as deep basin structure down to 1$\mathrm{km}$ depth (Pancha et al. 2017). The method has been standardised by the Consortium of Organizations for Strong-Motion Observation Systems "International Guidelines on Applying Non-invasive Geophysical Methods for Characterizing Seismic Site Conditions", with a companion paper discussing "best practice" analysis procedures towards obtaining reliable models from refraction microtremor measurements included in this volume (Louie et al. 2021).

The method averages the material properties beneath the length of the array. It is a volume-averaging surfacewave measurement, averaging velocities where geology is laterally variable, thus differing from single-point data obtained from downhole logs, as concluded by Raptakis (2012). The resultant 1D velocity-depth structure is therefore weighted towards deeper interfaces and lower velocities. Interpolation of closely spaced 1D velocity-depth profiles along transects allow 2D velocity-versus-depth cross-sections to be produced, which map the lateral velocity heterogeneity. These $2 \mathrm{D}$ cross-sections enable changes in the soil profile and geological structure to be characterised. Results also provide information that can be used as a first order reconnaissance tool targeting key areas for further, more costly investigation methods (e.g. boreholes, cone penetrometer testing (CPT), and test pits).

A primary benefit of utilising the geophysical measurements is the ability to extrapolate geotechnical knowledge between sparsely distributed and more costly investigation methods (e.g. boreholes, CPT investigations, and test pits) towards increasing spatial sampling density so that background and anomalous conditions can be identified early in the investigation.
Geotechnical field investigations such as CPTs can often be limited due to the rig encountering practical refusal in gravels or buried construction debris, thereby providing an incomplete vertical profile. Boreholes and downhole shear-wave techniques are more reliable, but are costly, and only provide point measurements at a specific location. In contrast, ReMi can detect velocity inversions, and as such, is commonly used to measure shear-wave velocity profiles for engineering applications.

However, like the MASW surface wave method, ReMi suffers from non-unique interpretations, meaning that a given data set can be represented by multiple subsurface geological models. Trade-off between layer thickness and the material property generates the issue of non-unique modelling results, and as such, neither the thickness nor the material property of the layer can be independently determined. To obtain a valid model, independent physical evidence and constraints from geotechnical investigation tests are incorporated into the interpretation of the data to further constrain the possible velocity models.

Three case studies presented in this paper demonstrate the benefits of incorporating the shear-wave velocity estimates from ReMi into the geotechnical investigations. These include identifying the location of buried stream channels, characterising palaeotopographical features, identifying areas of low velocity which may be prone to liquefaction, and assessing the thickness and velocity variations within geological units between geotechnical point investigation locations. We demonstrate how the use of ReMi minimises geotechnical risks by enhancing the ability to obtain a more thorough geological understanding of subsurface conditions, and providing information regarding subsurface material properties, and hence minimising geotechnical risks. Use of multiple methods supports thorough understanding of subsurface conditions enabling adoption of appropriate geotechnical design parameters to support the fundamentals of "good design".

\section{Depth and resolution of investigation}

Although initially developed by Louie (2001) for the determination of average shear-wave velocities to $30-\mathrm{m}$ depth (Vs30), the surface-wave theory behind the ReMi technique can be applied to a multitude of applications at various scales. The ability of any surface-wave 
seismic array to image velocity structure at any depth depends on the capability of the array to capture ground motion at wavelengths that sample the target depths. The wavelength content of the recorded data depends on several factors. These include the array length, geophone spacing, geophone frequency (the lowerfrequency limit of motion detection), the time duration of the data records, the frequency content of the noise sources producing the recorded ground motions, and the material properties.

ReMi has been widely used for engineering applications to image very shallow subsurface material structure in the upper $10 \mathrm{~m}$, using short geophone spacings between 0.5 and $3 \mathrm{~m}$ combined with high-frequency geophones to successfully image near-surface shallow structure. For imaging of deeper structure, longer array lengths, along with larger geophone spacing and lower frequency geophones, can be utilised. The longer arrays and lower frequency geophones ensure that the longerwavelength Rayleigh waves that sample deeper into the Earth's structure are captured by the recorded seismic data. Many studies have used the ReMi methodology with extended array lengths to successfully image subsurface velocity structure down to $200-\mathrm{m}$ depth. In addition, 3-km and 6-km-long arrays have been deployed to characterise basin geometry to $1-\mathrm{km}$ depth (Pancha et al. 2017). Total array length should generally be greater than twice the maximum target depth. Rayleigh waves are most sensitive to velocities and structures that are within a half-wavelength of the surface. To properly determine the velocity of such a wave, the sensor array needs to be at least as long as the wavelength.

\section{Key benefits}

A primary benefit of utilising ReMi measurements for geotechnical ground characterisation is the ability to increase spatial sampling density so that background and anomalous conditions can be identified early in the investigation. Because conventional seismic equipment is used to record data, and ambient noise is used as a seismic source, the ReMi method is less costly, faster, and more convenient than borehole methods and other surface seismic methods to determine shear-wave velocity (Vs) profiles. The method works best in seismically noisy settings, so it can be used on busy construction sites and areas where other intrusive methods are challenging. Non-urban settings can also be dominated by ambient noise by ocean-wave action, fast flowing rivers, rivers, and tree roots moving in the wind. In locations where both ambient anthropogenic and natural environmental noise is absent, ReMi investigations can still be undertaken by generating surface wave energy sources to produce surface Rayleigh waves that travel parallel to the seismic array. These energy sources include running or driving vehicles alongside geophone arrays and off-end hammer shots at both ends of the array. The method thus affords itself as an effective tool for both reconnaissance for and extrapolation of more expensive geotechnical spot measurements.

Several investigation techniques are routinely used in engineering practice to assess potential for seismic soil liquefaction. These include standard penetration test (SPT), cone penetration test (CPT), and Vs. Traditional SPT- and CPT-based assessments rely on a stress-based framework and empirical liquefaction triggering relationships (Boulanger and Idriss 2014) that require indirect methods of calculating soil properties (i.e. soil behaviour type index or fines content from CPT). Thus, there is potential for large uncertainty in this traditional approach, and therefore, reliance on a single method can cause bias in the liquefaction assessment. Vs testing measures a fundamental material property of the soil and offers engineers an additional tool to evaluate liquefaction resistance of sandy soils.

Vs measurements for sandy soils have been used to determine the seismic resistance of soil to liquefaction (Andrus and Stokoe II 2000). These relationships between Vs velocity and liquefaction potential are continually being refined (e.g. Zhou and Chen 2007; Kayen et al. 2013; Dobry et al. 2015) and have demonstrated that soils with low Vs velocities are more susceptible to liquefaction. For many of the case studies presented below, the shear-wave velocity data from ReMi are used in conjunction with CPT, SPT, and laboratory particle size distributions in the assessment of liquefaction potential.

ReMi surveys aid in quickly and economically extending subsurface characterisation over larger areas, correlating between the boreholes, test pits, and other investigation data points to characterise lateral changes in geology and/or material properties. A major advantage is that the method often allows for the assessment of ground conditions to deeper depths than traditional shallow geotechnical investigation measurement techniques. By providing details regarding different material properties of the sub-surface ground conditions, ReMi 


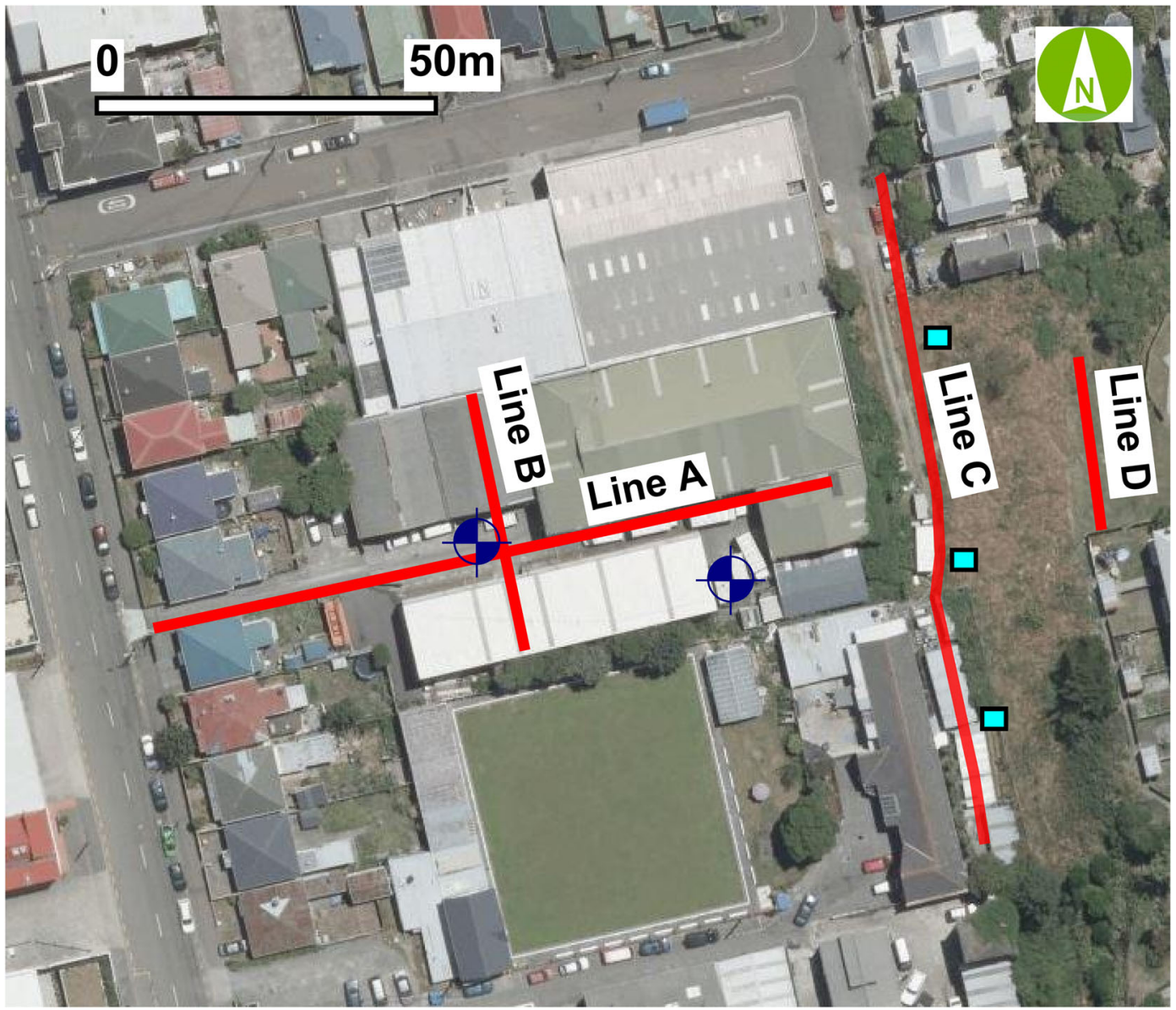

Fig. 1 Locations of the ReMi seismic arrays (soil lines) undertaken for the geotechnical investigation for a Terrace Townhouse development. Borehole (circular symbols) and test pit (squares) locations are displayed. Aerial photograph sourced from LINZ
Data Service (https://data.linz.govt.nz/data/category/aerial) and licensed under the Creative Commons Attribution 4.0 New Zealand velocity models contribute towards the development of a more integrated site model.

\section{Case studies}

Aurecon New Zealand Limited has utilised ReMi towards supplementing data between sparsely distributed and more expensive geotechnical spot measurements (e.g. boreholes, CPT and SPT data, test pits). We present three case studies to demonstrate the benefits of incorporating the Vs velocity estimates from ReMi into geotechnical investigations. In all three cases, forward modelling of the Rayleigh wave dispersion data is used to obtain the velocity-versus-depth models. Results allow the correlation and extrapolation of geotechnical knowledge between geotechnical investigation locations, and the further assessment of subsurface material properties.

\subsection{Terrace Townhouses-Wellington, New Zealand}

To supplement data between geotechnical borehole and test pit investigations, ReMi investigations were undertaken to determine the sub-surface velocity structure beneath the site of the proposed Terrace Townhouses (Fig. 1). 2D velocity-versus-depth cross-sections mapping the lateral velocity heterogeneity beneath Line A and Line $\mathrm{C}$ are presented in Fig. 2.

Borehole data that included SPT and geological soil descriptions from two locations along Line A were used 


\section{(a) Line A}

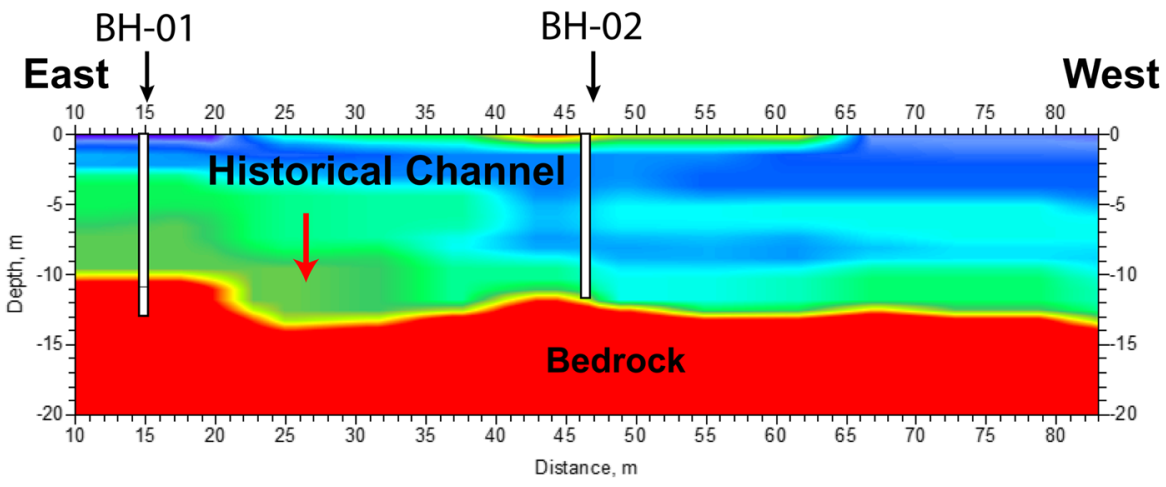

\section{(b) Line C}

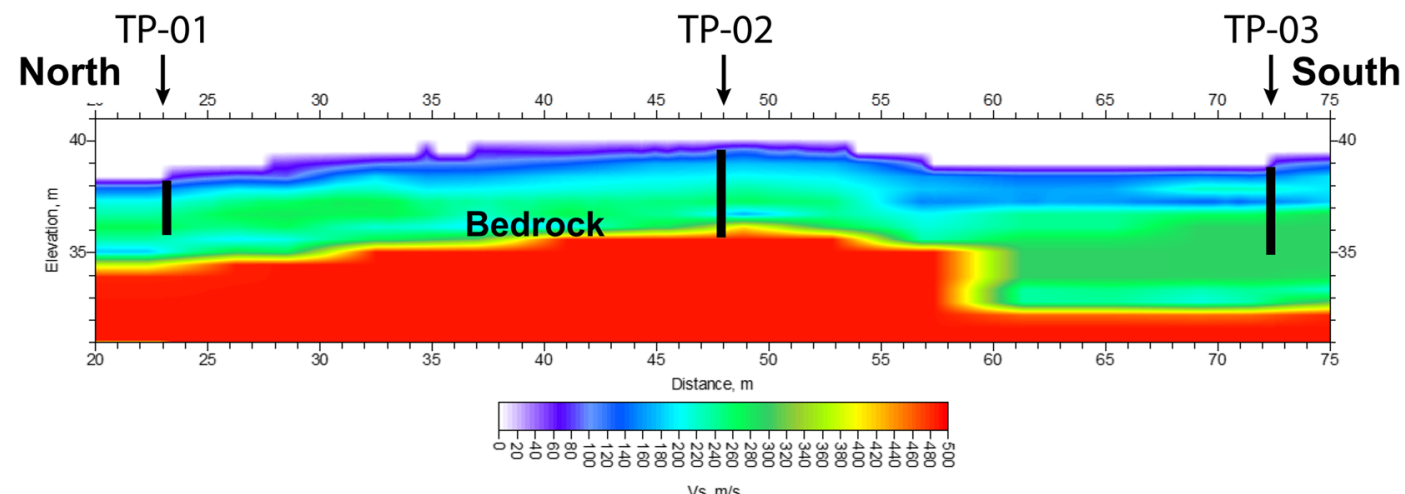

Fig. 2 2D shear-wave velocity cross-section beneath (a) Line A and (b) Line C. Borehole BH-01 and BH-02 terminated at the weathered bedrock interface. Relative locations of the seismic arrays are displayed in Fig. 1. The shear-wave velocity scale displayed below each figure ranges from 0 to over $500 \mathrm{~m} / \mathrm{s}$, with bedrock velocities $>500 \mathrm{~m} / \mathrm{s}$. Warm colours indicate high velocities, while cooler colours indicate low velocities. Test pit locations and depth extent are displayed as black lines in section (b). Both sections have approximately no vertical exaggeration to constrain modelling of the velocity profiles. Both boreholes terminate at the bedrock interface. These constraints allowed 2D velocity-depth cross-sections beneath each seismic array to be produced, and thereby extrapolating site condition knowledge across the entire investigation site. As seen from Fig. 2(a), there were notable lateral changes, which highlight areas of low Vs velocity that assisted with the liquefaction assessment of the site, when combined with the CPT, SPT, and sediment grain size information from borehole samples. The non-intrusive technique was also able to define the location of a historical buried stream channel along Line A (Fig. 2(a)), which is documented to have traversed the site during the mid-1800s (Bastings, 1936). Without data from the geophysical ReMi investigation, the location of a buried stream channel and associated palaeo- topographical features would otherwise have been unknown.

Velocity modelling and interpretations along Line $\mathrm{C}$, shown in Fig. 2(b), were controlled by stratigraphy from three test pits. Bedrock was only encountered in one test pit, TP-02. An abrupt change in bedrock depth and soil thickness was revealed by the investigation. The development site was the location of a historic brick factory (circa 1895), which extracted clay material in the immediate vicinity. The increase in bedrock depth observed along Line $\mathrm{C}$ is interpreted to be anthropogenic in nature and was undetected and unforeseen from the geotechnical investigation.

The ReMi investigations allowed the correlation and extrapolation of geotechnical data between investigation locations, mapping lateral variations, and the further 


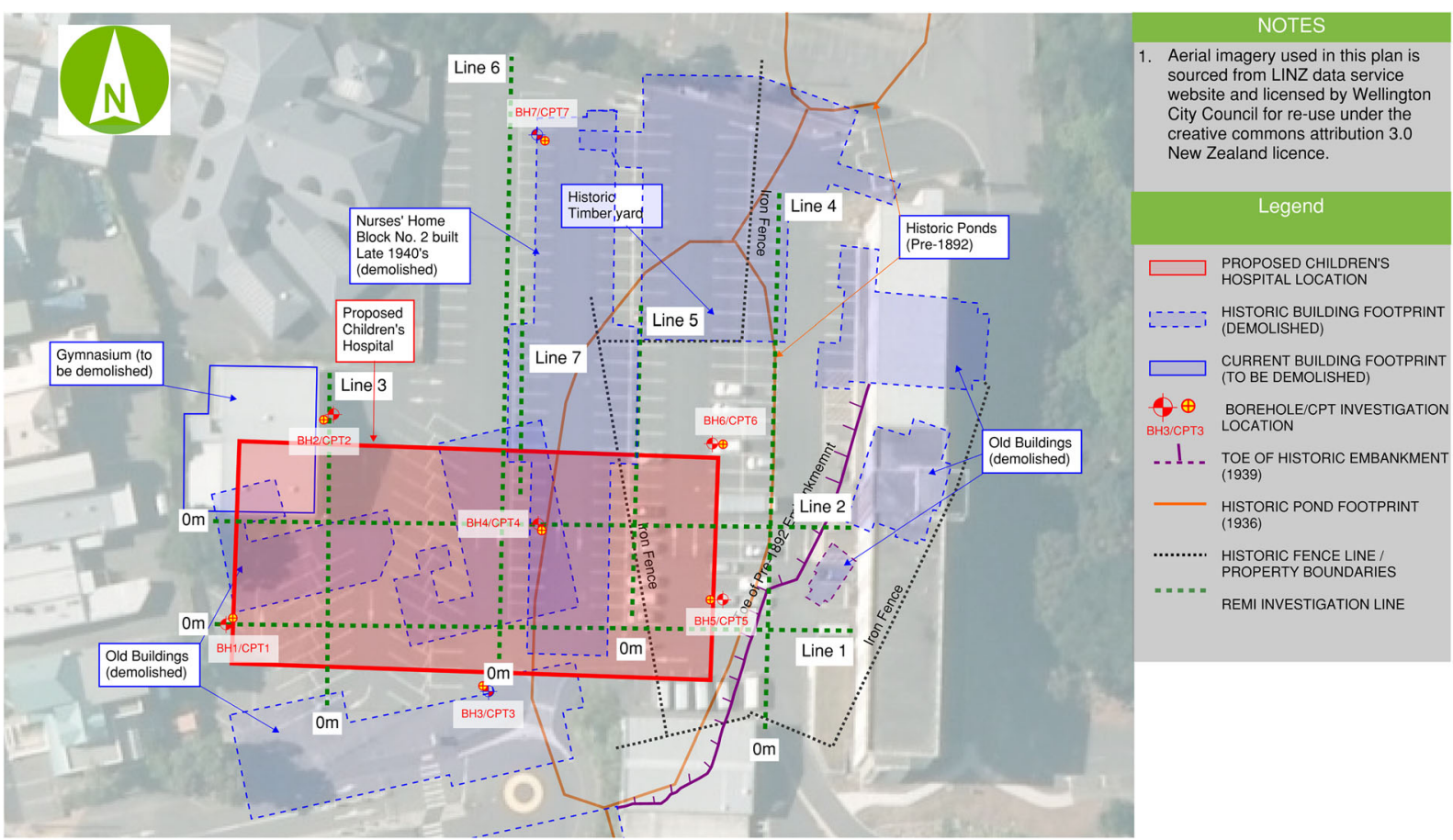

Fig. 3 Map showing locations of the seven seismic array lines used to determine bedrock and soils structure beneath the site of the proposed Wellington Children's Hospital. Previous site developments and historical natural features are also displayed

assessment of material properties. More importantly, the technique permitted the assessment of material properties to greater depths than the shallow test pits and boreholes. Use of ReMi in conjunction with boreholes and test pits for the Terrace Townhouse project enabled the ability to acquire a more comprehensive assessment of site conditions than traditional methods allowed.

\subsection{Wellington Children's Hospital—Wellington, New Zealand}

In 2018, Wellington Children's Hospital Charity Limited $(\mathrm{WCH})$ has begun construction of the new children's hospital on an existing carpark site, immediately to the north of the Wellington Hospital complex. The proposed building comprises a ground floor for car parking and three stories of wards built above the ground floor. WCH engaged Aurecon New Zealand Limited to provide an initial geotechnical assessment of the site. Experience from sites in the vicinity indicated variable layers of fill (including potential infilled gully/streams and ponds), underlain by undifferentiated alluvium and greywacke sandstone bedrock with an extensive weathering profile were likely to form the geological profile at the site. As part of the geotechnical investigations, ReMi seismic investigations were carried out to determine the subsoil structure and estimate the subsoil shear wave velocity profiles to:

- Characterise the lateral variation of soil lithology and soil properties across the site.

- Determine variations in the bedrock depths across the site.

- Calculate engineering properties of soils and rock such as low-strain elastic and shear moduli.

- Assist with the determination of liquefaction potential across the site.

The site has a long and complex history of building development. Early maps indicate that site was originally a natural drainage pathway that included a swamp area and several ponds. Over the course of human occupation and subsequent building developments, successive infilling has occurred up to present day. Aerial photographs dating back to 1923 through to the present day of Wellington Hospital show numerous historical buildings have occupied the investigation area. Historical records were used to 

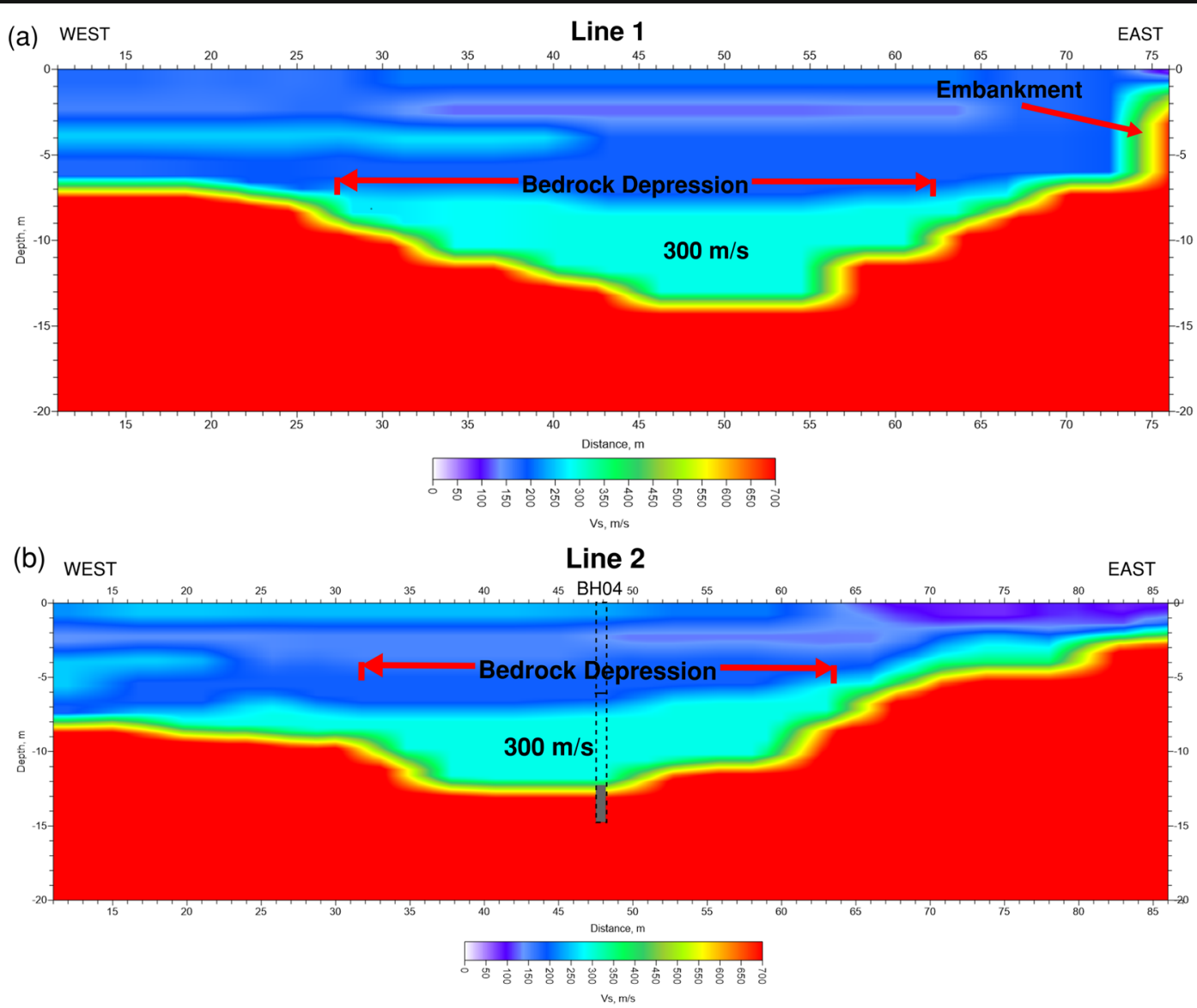

Fig. 4 2D S-wave velocity (Vs) model along (a) Line 1 and (b) Line 2. Distances are from the beginning of each array as shown in Fig. 3. Both sections have approximately no vertical exaggeration

determine the locations of old structures that previously occupied the site. In addition, maps by Bastings (1936) indicated that an embankment existed along the western side of the investigation site. Figure 3 illustrates the locations of the proposed building site, the historical buildings, and the old drainage features. The site is known to have been underlain by 2.6 to $6 \mathrm{~m}$ of nonengineered fill underlain by alluvial soils. The nonengineered fill was very loose and included concrete pieces, bricks, wood, nails, metal sheets, metal pieces, old pipes, and isolated layers of decomposed vegetation.

The ReMi investigation for the site included seven seismic arrays, Line 1 to Line 7 (dashed green lines), between 47 and $92 \mathrm{~m}$ long, and the locations of which are also shown in Fig. 3. Results of the ReMi survey demonstrate that in general, the reclamation fill deposits consist of materials with a relatively low Vs velocity compared to the underlying alluvial soils. Vs velocities of the non-engineered fill range between $\sim 125$ and $250 \mathrm{~m} / \mathrm{s}$, while the alluvium/colluvium overlying the bedrock range between $\sim 175$ and $400 \mathrm{~m} / \mathrm{s}$. In comparison, the highly weathered greywacke sandstone bedrock velocities varied between 300 and $600 \mathrm{~m} / \mathrm{s}$, with $>700 \mathrm{~m} / \mathrm{s}$ for the more competent rock.

Based on the historic evidence, both Line 1 and Line 2 traverse the historical pond, which has undergone progressive reclamation during the development of the land. The 2D velocity cross-sections for Line 1 and Line 2 are shown in Figs. 4(a) and b respectively. As seen in the cross-sections, the bedrock depth varies, delineating a depression within the bedrock terrain. Along Line 1, the greywacke sandstone bedrock interface is deepest towards the eastern end of the array, with a maximum depth of $13.6 \mathrm{~m}$. Towards the western end, the bedrock is at 6-m depth below the ground surface, consistent with observations from $\mathrm{BH} 01$. Where the bedrock deepens, a $300 \mathrm{~m} / \mathrm{s}$ layer overlies the bedrock surface. Based on correlations with the geotechnical boreholes, 
Fig. 5 2D S-wave velocity (Vs) model along Line 3. Distances are from the beginning of the array as shown in Fig. 5. The circled area highlights a zone of high velocity likely associated with the location of an historical structure. The section has approximately no vertical exaggeration

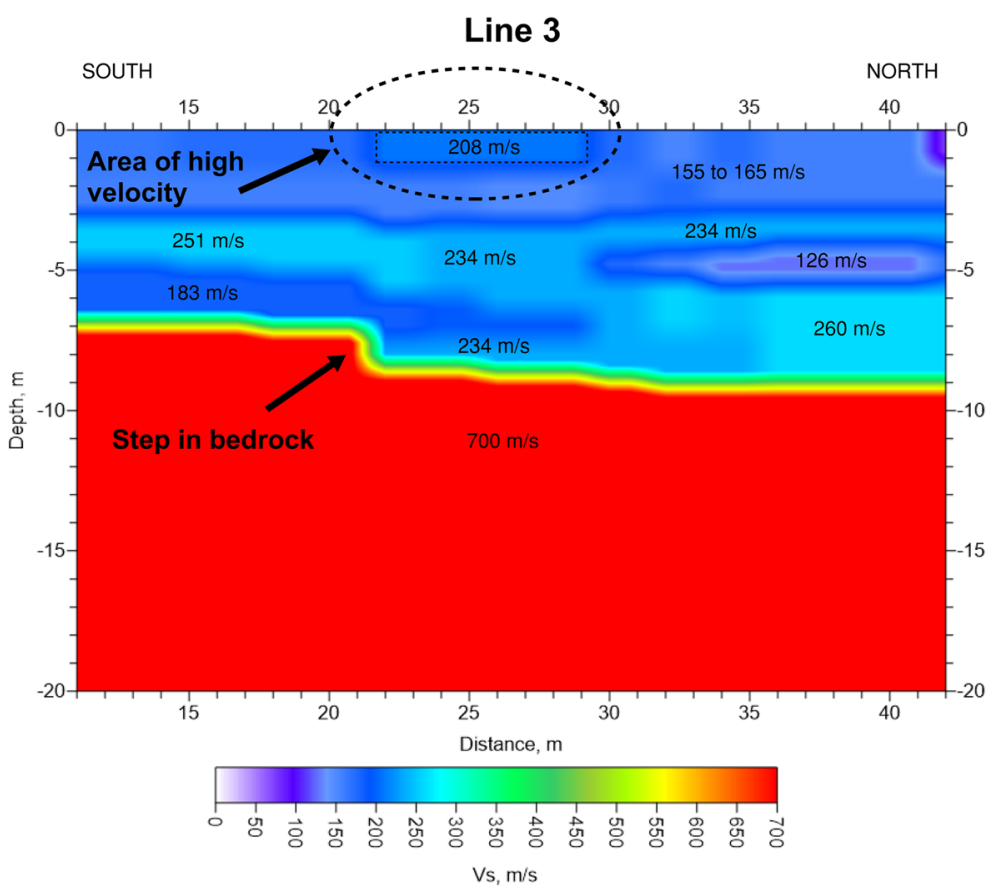

this $300 \mathrm{~m} / \mathrm{s}$ layer likely represents gravels associated with the undifferentiated alluvium. For Line 2, the bedrock interface is also deepest nearer the centre of the array, with a maximum depth of $12.3 \mathrm{~m}$, and shallows towards both the west and the east. For both Line 1 and Line 2, bedrock is shallowest towards the eastern side of the site, near the location of the historical embankment, shown in Fig. 3. Evidence of the embankment is imaged at the eastern end of Line 1 which traverses the embankment, while Line 2 does not.

Line 3 is in a north-south orientation along the western side of the site. A 2D plot of the velocity-depth cross-section determined below this array is presented in Fig. 5. A notable $1.5 \mathrm{~m}$ step down in the bedrock profile occurs at approximately $21.5 \mathrm{~m}$ along the array. Between 21 and $27 \mathrm{~m}$ distance along the array, an area of slightly higher velocity is noted in the upper $1.3 \mathrm{~m}$ below the surface. This region of low velocity coincides approximately with the presumed location of an old structure demolished pre-1943, as seen in Fig. 3. It is likely that the $1.5-\mathrm{m}$ step which occurs in the bedrock profile at $21.5 \mathrm{~m}$ along the array is also associated with the footprint of this demolished building.

The largest historical structure that encroached onto the site building is the Nurse's Home Block No.2, built in the late 1940s and demolished in 2010. Historical photos together with the original building plans allowed the approximate location of the foundation, to be determined, as illustrated in Fig. 3. Building plans, together with photographs taken during the 2010 demolition (Fig. 6a), documented that the reinforced rebar building foundations were still present and entrenched at approximately $5.5 \mathrm{~m}$ apart. To resolve the detailed soil structure of the fill material in the upper $5 \mathrm{~m}$ of the surface and detect buried building foundations associated with the demolished Nurses' home (shown in Fig. 3), data acquisition along Line 7 was acquired using a shorter geophone spacing of $0.5 \mathrm{~m}$, compared to $1 \mathrm{~m}$ for the remaining seismic arrays. Results of the analysis are presented in Fig. 6(b). The Vs velocity of the fill material in the upper $2 \mathrm{~m}$ of the soil profile is found to be highly variable. In addition, the analysis detected the presence of areas with a very high Vs velocity. Subsequent excavations revealed that the ReMi analysis correctly estimated the locations of the rebar-reinforced foundations.

\subsection{City Rail Link - Auckland, New Zealand}

The City Rail Link is a rail project currently under construction in Auckland, New Zealand. The $\$ 4.4$ billion project consists of the construction of a $3.5-\mathrm{km}$-long double-track rail tunnel underneath Auckland's city centre, between the Harbour and Mt Eden Train Station. 
(a)

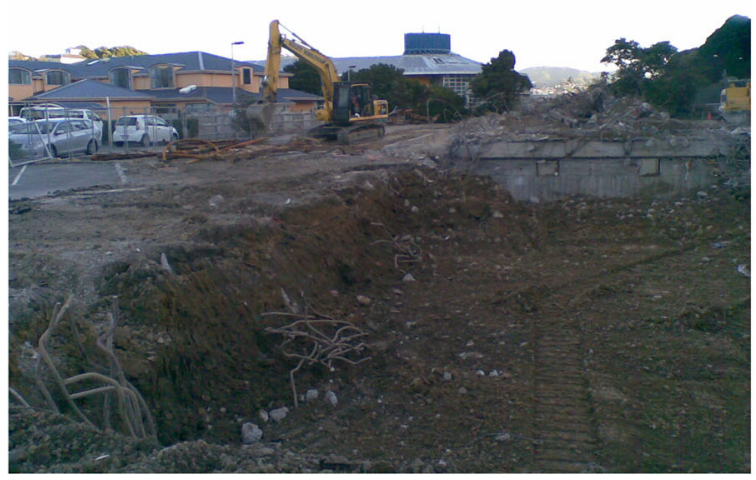

(b)

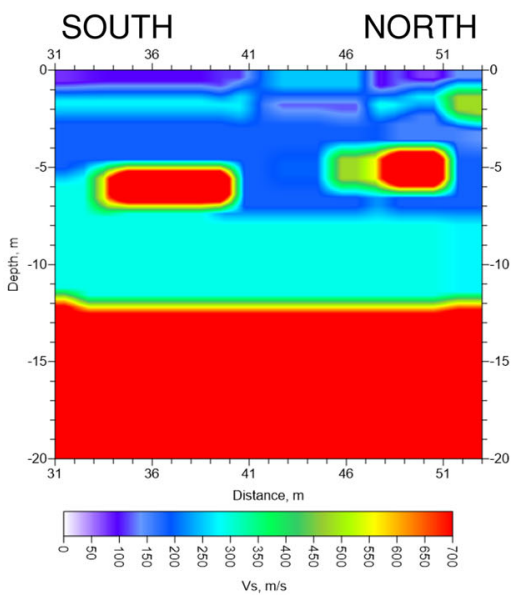

Fig. 6 (a) Photo showing reinforcement rebar from the foundations of the Nurse's Home Block No.2 during demolition in 2010. (b) 2D S-wave velocity (Vs) model beneath Line 7. Distances are

As well as the construction of the tunnel, the City Rail Link adds two new underground stations. When finished, it will allow trains to pass through most Auckland stations every 5 to $10 \mathrm{~min}$ at peak times.

However, an existing stormwater pipe was in the path of the new City Rail Link tunnels route near Mt Eden Train Station. The area has a history of adverse ground conditions and associated engineering difficulties. Three volcanoes, with quite different characteristics, occur to relative to the beginning of Line 6 as shown in Fig. 3. The section has approximately no vertical exaggeration

the north and south of the rail alignment. These volcanoes have produced ash and lava deposits, which are mixed in with soft sediments from historical swamps and ponds, hard basalt rock, and sandstone. The extrusive basalt deposits themselves are complex, containing scoria and voids. Geological interpretations indicate that the Mt Eden site was affected by a palaeo-channel that had eroded into older sediment and rock, and in places, were infilled by basalt flows. When the existing

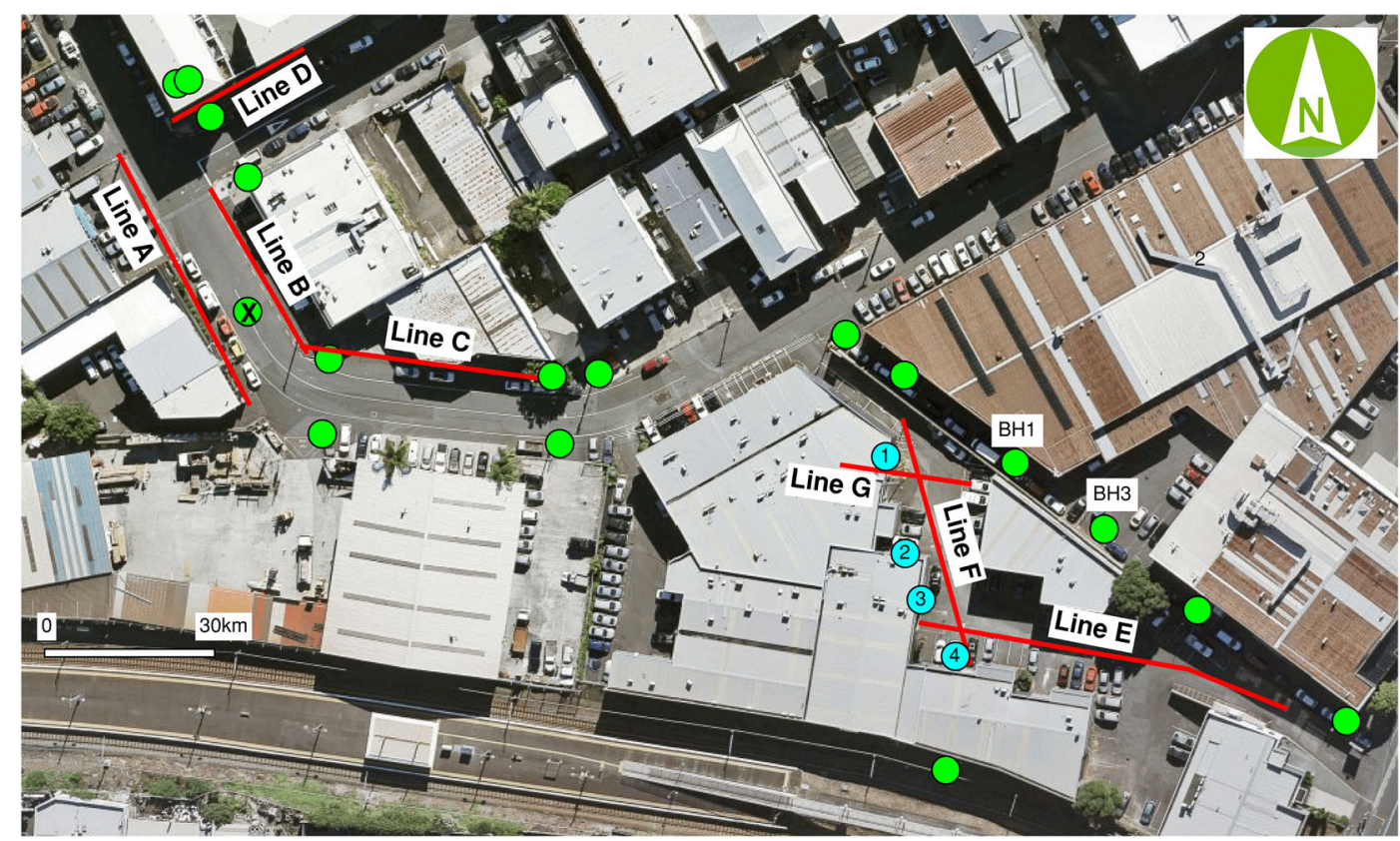

Fig. 7 Locations of the ReMi seismic arrays (red) near Mt Eden Train Station. Green cirlces show boreholes nearest the seismic survey locations at the time of the investigations. The cyan circles show boreholes drilled after the ReMi investigations. Labels refer to the boreholes shown in Fig. 8 
Fig. 8 (a) Dispersion curve picks and matching fits from blind modelling (blue) of the velocitydepth profile and the model obtained when using constraints from borehole observations. (b) Resultant velocity-depth models for the blind (blue) and constrained (red) modelling. Note that both models match the observed data
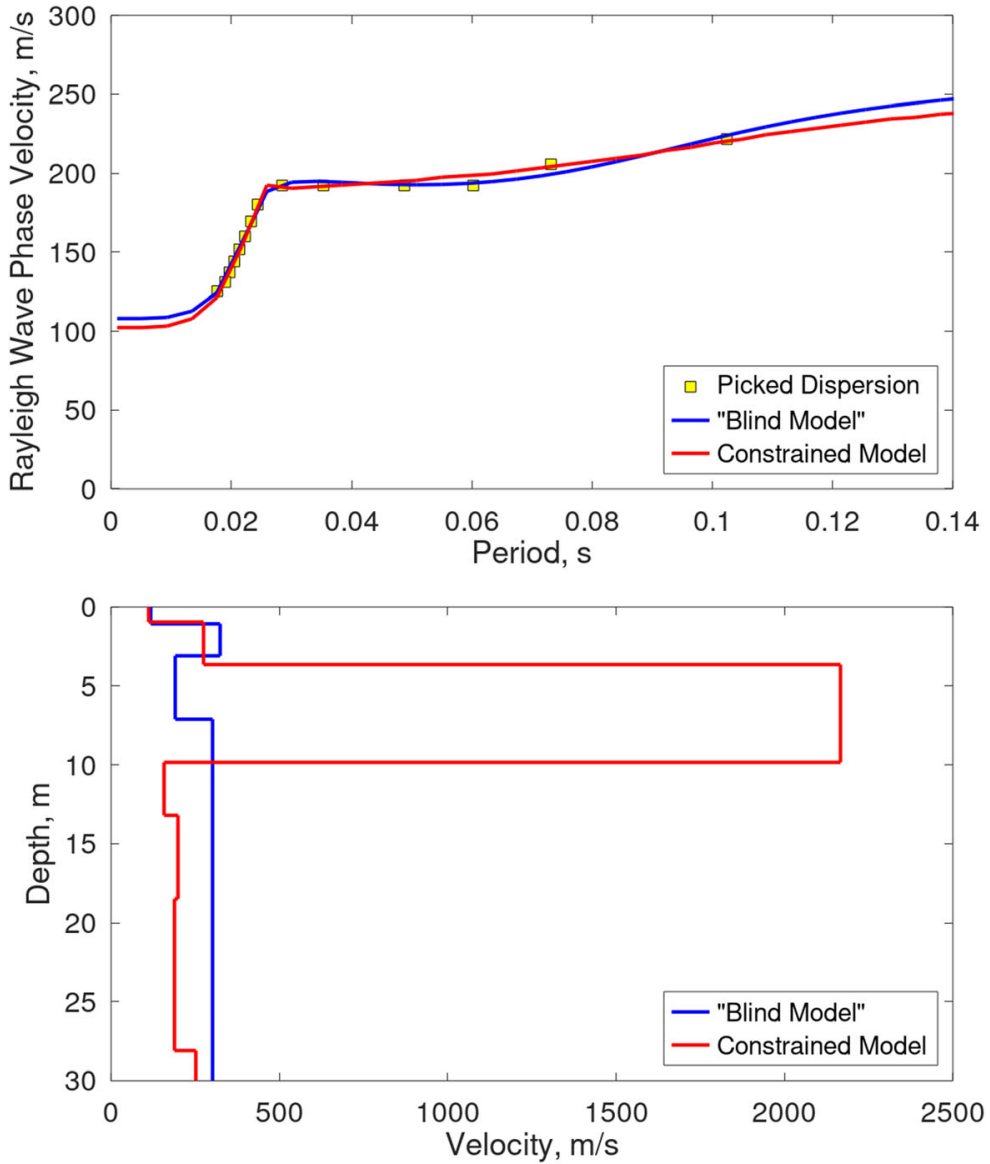

stormwater pipe was being constructed, the first tunnelling attempt unexpectedly encountered basalt, and the second attempt encountered unanticipated very soft ground. Although the presence of the channel was known, there were uncertainties about its exact extents: depth, width, and axial position. Previous attempts to image to top of the basalt flows using geophysical

Table 1 Data acquisition parameters for the seven seismic arrays shown in Fig. 3

\begin{tabular}{llll}
\hline & $\begin{array}{l}\text { Geophone spacing } \\
(\mathrm{m})\end{array}$ & $\begin{array}{l}\text { Number of } \\
\text { channels }\end{array}$ & $\begin{array}{l}\text { Array length } \\
(\mathrm{m})\end{array}$ \\
\hline Line A & 1.5 & 47 & 69 \\
Line B & 1 & 35 & 34 \\
Line C & 1 & 47 & 46 \\
Line D & 1 & 41 & 40 \\
Line E & 2 & 33 & 64 \\
Line F & 1 & 46 & 45 \\
Line G & 1 & 24 & 23 \\
\hline
\end{tabular}

ground penetrating radar failed due to the noise generated by thick layers of subsurface fill materials and the presence of pavement. Likewise, available borehole data were unable to delineate the exact axis of the flow.

ReMi was used to supplement the existing borehole investigation towards mapping basalt depths. The scope of the investigation was to identify locations where a pipe-jack route for a storm-water realignment would potentially encounter basalt along the axis of the palaeo-channels. The avoidance of basalt was imperative to avoid major project delay and associated financial ramifications.

Seven seismic arrays, as shown in Fig. 7, were deployed, but locations were constrained by limited available space due to the urban surroundings. Array lengths and instrument spacing for each of the seven arrays are provided in Table 1. Once the arrays were deployed, passive noise data was recorded at a sampling rate of $2 \mathrm{~ms}$ for intervals of $20.48 \mathrm{~s}$ each. Twenty to thirty noise records were made along each seismic deployment. 

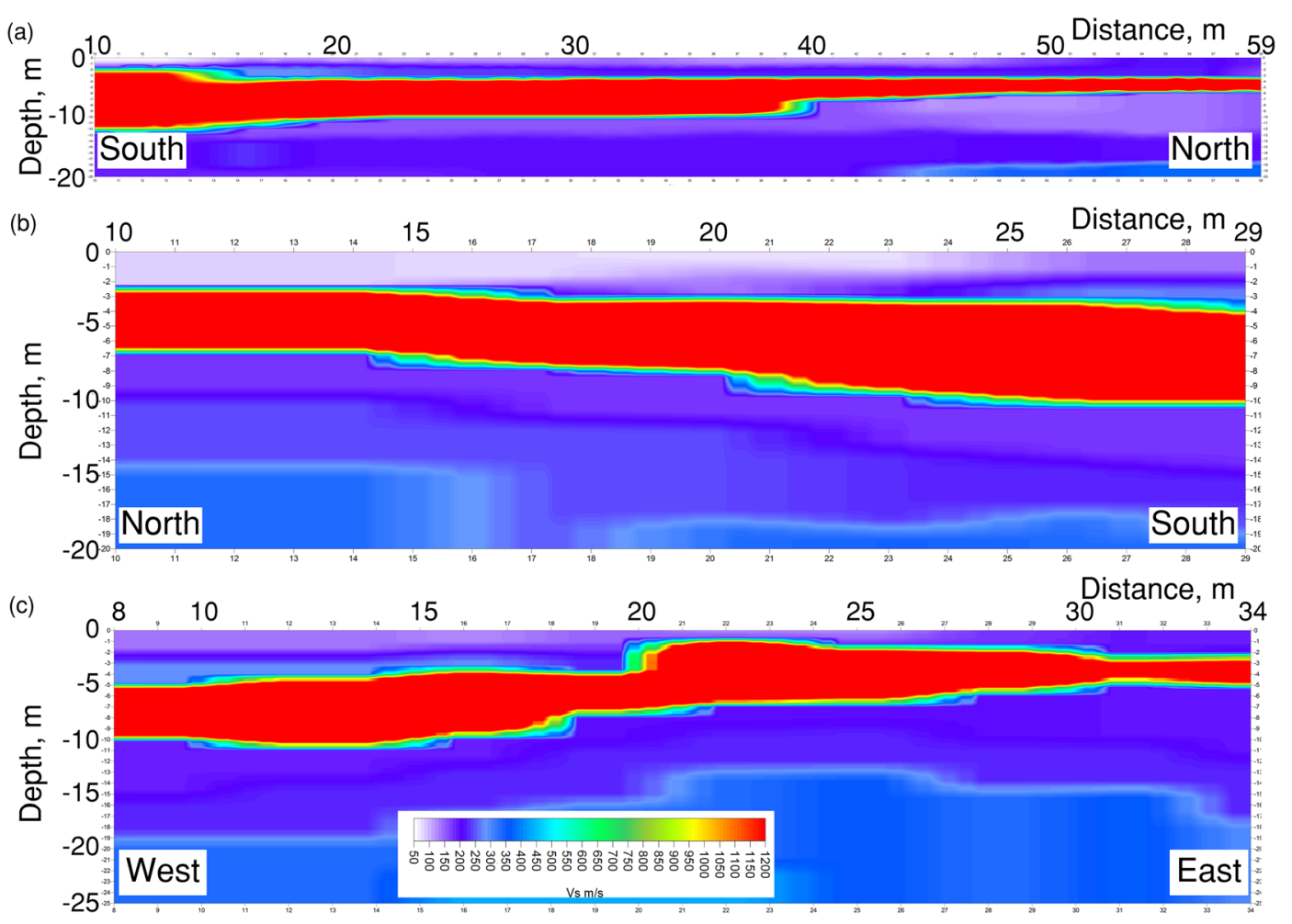

Fig. 9 Delineation of a basalt flow beneath (a) Line A, (b) Line B, and (c) Line C. The shear-wave velocity scales displayed below each figure range from 50 to $+1200 \mathrm{~m} / \mathrm{s}$. Warm colours indicate

\subsubsection{Modelling of the velocity-depth profiles}

The main issue with the use of geophysical surface wave techniques is the non-uniqueness of the resultant velocity-versus-depth model. Like the MASW, SPAC, and SASW surface wave methods, ReMi suffers from non-unique interpretations, meaning that a given data set can be represented by multiple subsurface geological models (Louie 2001). Trade-off between layer thickness and the material Vs velocity generates the issue of nonunique modelling results, and as such, neither the thickness nor the velocity of the material layer can be independently determined. Towards obtaining a valid model, independent physical evidence and constraints from geological observations and geotechnical investigation tests must be incorporated into the interpretation of the data.

Typical Vs velocities of basalt range from 2700 to 3200 $\mathrm{m} / \mathrm{s}$, as documented by Press (1966) and Hatheway and Kiersch (2000). "Blind modelling" of the Rayleigh-wave dispersion data produced velocity-versus-depth models that were absent of high velocities typical of basalt high velocities, while cooler colours indicate low velocities. The basalt was found to have a shear-wave velocity of $>1200 \mathrm{~m} / \mathrm{s}$ (red)

deposits. This absence of high velocities was noted when both analysing data along the entire length of each array, as well as shorter subsets of consecutive geophone instruments. An example of the resultant velocity-versus-depth profile obtained through "blind modelling" using recorded data along a $15-\mathrm{m}$ segment is given in Fig. 8 . The $15-\mathrm{m}$ sub-array is centred on the borehole marked " $X$ " in Fig. 7. As seen in Fig. 9, the initial "blind" model matches the observed dispersion picks well (blue lines in the graph shown in Fig. 8(a) and 8(b)). However, the presence of high velocity basalt is not observed in the model, owing to the non-uniqueness of the solution.

Observed data from borehole investigations allowed calibration of the velocity structure and assisted in the verification of the derived models. Knowledge from the nearby existing borehole log, marked " $X$ " in Fig. 7, $6.5 \mathrm{~m}$ from the line, was used to help constrain the velocityversus depth model. Basalt was observed to occur between 3.5 and $9.75 \mathrm{~m}$ within the borehole log. During the forward modelling of the velocity-versus-depth profile for this location, basalt was restricted to occur between 3.5 and $9.8 \mathrm{~m}$ in accordance with the borehole observations, and a 
Vs velocity typical of basaltic deposits was specified. This "constrained" velocity profile is compared with the velocity-versus-depth profiles obtained from initial "blind" forward modelling of the dispersion curve data without use of known constraints in Fig. 9. Using this constrained velocity-depth profile at this reference location, together with other available borehole data, the variation in the recorded data along Line A in either direction of this point was used to determine the lateral changes in basalt thickness.

\subsubsection{Results}

The 2D Vs velocity profiles below Line A, Line B, and Line $\mathrm{C}$ shown in Fig. 9 map the lateral variation in basalt depth and thickness along each array. The ReMi technique was able to delineate both an upper and lower basalt surface and characterise the sediments beneath.
Below Line A (Fig. 9a), the depth to the base of the basalt varies along the line, from approximately $12 \mathrm{~m}$ depth to the south-east to $5 \mathrm{~m}$ towards the north-west, consistent with borehole data. This northward thinning of the basalt flow agrees with the general trend of the palaeo-valley axis down the centre of the street and reflected in the modelled basalt flow beneath Line B (Fig. 9b).

Significant variation in the depths to the top of basalt, and the thickness of the flow were observed from data along Line C (Fig. 9c). Depth to the top of the basalt flow abruptly changes in depth at $21 \mathrm{~m}$ along the array. The recorded surface-wave data warranted this change, dictating the need for the shallowing and thickening of the basalt flow to match the observed dispersion data. Depicted features along the base of the basalt flows are interpreted as a geomorphic characteristic of the alluvial valley that was being infilled by the lava.

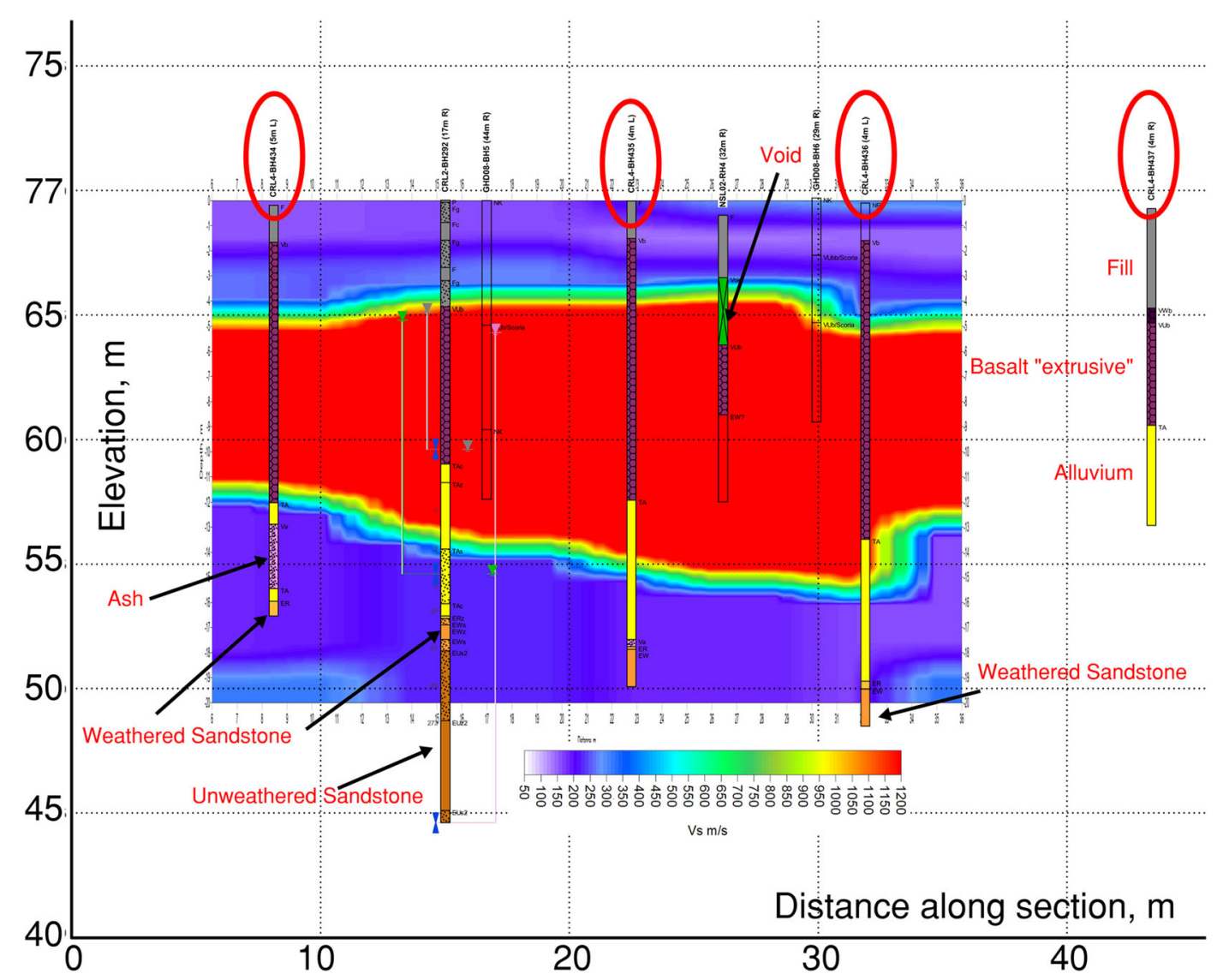

Fig. 10 Delineation of a basalt flow beneath Line F using the ReMi technique. Colours displayed are as for Fig. 9. Results from this investigation were used to strategically place an additional four borehole (circled in red) to verify these findings. Figure 7 shows the location of these boreholes 
Results beneath Line F, which are presented in Fig. 10, demonstrate that ReMi provided an effective representation of the thickness of the basalt flow but struggled with absolute depth of the flow. The geophysical information helped constrain basalt depths prior to selection of further borehole locations for a second stage of the geotechnical investigations. Boreholes drilled during this second stage are circled in red in Fig. 10 and are represented by the cyan numbered circles in Fig. 7. The additional borehole data demonstrated that the ReMi investigation accurately located the axis of the channel, correctly estimated the general shape of the basalt flow, and defined the top and base of the basalt deposit within $\pm 2 \mathrm{~m}$ depth. The ReMi analysis correctly captured the thickest portion of the basalt, as well as the thinning of the flow towards the south-east. Moreover, ReMi was able to highlight the low velocities of the alluvium and weathered bedrock beneath the base of the basalt flow, where the pipe-jack route would be excavated.

Results from the City Rail Link investigation demonstrate how the ReMi technique is a valuable reconnaissance tool. For large-area geotechnical investigations, geophysical data can be acquired over much of the site at relatively low cost to identify areas to target with traditional, but more expensive geotechnical investigation methods. Knowledge of depths and thicknesses of the basalt flows along the realignment was essential for the success of the project. Together with a comprehensive three-dimensional geological model constructed from borehole data (Kirk and Ireland 2019), the geophysical investigation reduced uncertainty and financial risk associated with drilling of the realignment tunnel.

\section{Conclusion}

Geotechnical engineering is one of the most challenging engineering disciplines. All too often unexpected ground conditions are encountered. Using refraction microtremor (ReMi) surveys, we can remove some of the mystery surrounding the ground conditions between spot measurements. Refraction microtremor seismic investigations supplement the overall geotechnical investigation, enabling better characterisation of the variation of soil and rock properties across investigation sites. Results presented here demonstrate how ReMi can be used as a cost-effective first order reconnaissance tool targeting key areas for intrusive investigations, and towards providing a comprehensive site characterisation and assessment. The objective is not to replace traditional geotechnical investigations but complement them to obtain a more comprehensive assessment of engineering site conditions. Results from the case studies demonstrate how the use of ReMi, as part of a multidisciplinary ground investigation, enhances the ability to obtain a thorough geological understanding of sites and hence minimising geotechnical risks.

Acknowledgements We would like to express our gratitude to Dave Stewart from Stratum Management Ltd, for allowing us to present data from the Wellington Townhouse Development. Wellington Children's Hospital Charity Limited is the entity proposing to construct a new children's hospital. City Rail Link is the entity constructing a $3.5-\mathrm{km}$-long double-track rail tunnel underneath Auckland's City Centre. We would also like to than two anonymous reviewers for their valuable feedback. The Consortium of Organizations for Strong Motion Observation Systems (COSMOS) and a group of North American power utility companies, consisting of Southern California Edison and Pacific Gas and Electric, identified the need for these guidelines for best-practices and provided funding and encouragement to facilitate the project. Open Access publication fees for this paper were directly funded by COSMOS. This material is also based upon work supported by the US Geological Survey under Cooperative Agreement No. G17AC00058. The views and conclusions contained in this document are those of the authors and should not be interpreted as representing the opinions or policies of the US Geological Survey. The authors thank Alan Yong of the US Geological Survey, Pasadena Office, for coordinating this issue.

Funding Results presented are the result of consultancy work undertaken by Aurecon New Zealand Ltd and are the property of individual clients.

Data Availability Data and material are subject to contractual arrangements between Aurecon and its clients.

Code availability All ReMi software is copyright 2020 Optim Earth, Inc., and cannot be distributed. Optim is the only source for commercial SeisOpt ${ }^{\mathrm{TM}} \mathrm{ReMi} \odot$ data-collection and analysis services, through www.optimsoftware.com.

\section{Declarations}

Competing interests The ReMi technology is owned by the University of Nevada, Reno, and licensed exclusively to Optim Earth, Inc. (www.optimsoftware.com). Optim pays royalties to the University based on their commercial revenues from ReMi. As inventor of the technology, under University policy, John Louie personally receives a share of those royalties.

Disclaimer The views and conclusions contained in this document are those of the authors and should not be interpreted as 
representing the opinions or policies of the US Geological Survey. Mention of trade names or commercial products does not constitute their endorsement by the US Geological Survey.

Open Access This article is licensed under a Creative Commons Attribution 4.0 International License, which permits use, sharing, adaptation, distribution and reproduction in any medium or format, as long as you give appropriate credit to the original author(s) and the source, provide a link to the Creative Commons licence, and indicate if changes were made. The images or other third party material in this article are included in the article's Creative Commons licence, unless indicated otherwise in a credit line to the material. If material is not included in the article's Creative Commons licence and your intended use is not permitted by statutory regulation or exceeds the permitted use, you will need to obtain permission directly from the copyright holder. To view a copy of this licence, visit http://creativecommons.org/licenses/by/4.0/.

\section{References}

Andrus RD, Stokoe KH II (2000) Liquefaction resistance of soils from shear-wave velocity. J Geotech Geoenviron 126(11): $1015-1025$

Bastings L (1936) A subsoil survey of Wellington City. NZ Inst Archit 15(5):75-78

Boulanger RW, and \& Idriss I.M (2014) CPT and SPT based liquefaction triggering procedures. Report No. UCD/CGM.14,1 .

Coccia S, Del Gaudio V, Venisti N, Wasowski J (2010) Application of Refraction Microtremor (ReMi) technique for determination of 1-D shear wave velocity in a landslide area. J Appl Geophys 71(2-3):71-89

Dobry R, Abdoun T, Stokoe KH, Moss RES, Hatton M, El Ganainy H (2015) Liquefaction potential of recent fills versus natural sands located in high-seismicity regions using shearwave velocity. J Geotech Geoenviron 141(3):04014112

Hatheway AW, Kiersch GA (2000) Engineering properties of rock. In: Carmichael RS (ed) Handbook of Physical Properties of Rocks. CRC Press, Boca Raton, Florida, Vol. II
Kayen R, Moss RES, Thompson EM, Seed RB, Cetin KO, Kiureghian AD, Tanaka Y, Tokimatsu K (2013) Shearwave velocity-based probabilistic and deterministic assessment of seismic soil liquefaction potential. J Geotech Geoenviron 139(3):407-419

Kirk PA and Ireland TJ (2019) A 'whole-of-life' approach to project 3D ground-models: City Rail Link, New Zealand. Proceedings of Hong Kong Institute of Engineers, Geotechnical Division Annual Seminar April 2019.

Louie JN (2001) Faster, better: shear-wave velocity to 100 meters depth from refraction microtremor arrays. Bull Seismol Soc Am 91(2):347-364

Louie JN, Pancha A, Kissane B (2021) Guidelines and pitfalls of Refraction Microtremor surveys. J Seismol, this issue

Pancha A, Pullammanappallil S, Louie J, Cashman PH, Trexler JH (2017) Determination of 3D basin shear-wave velocity structure using ambient noise in an urban environment: a case study from Reno, Nevada. Bulletin of the Seismological Society of America 107(6):3004-3022. https://doi. org/10.1785/0120170136

Press F (1966) Seismic Velocities. In Handbook of Physical Constants, S. P. Clark (Editor). Geol Soc Am Memoir 97:587

Pullammanappallil S (2006) Geotechnical and geophysical case studies involving the Refraction Microtremor (ReMi) method for shear wave profiling. 2006 Highway Geophysics Conference, December 5-7, St. Louis, Missouri.

Raptakis DG (2012) Pre-loading effect on dynamic soil properties: seismic methods and their efficiency in geotechnical aspects. Soil Dynamics and. Earthq Eng 34:69-377

Rucker ML (2003) Applying the refraction microtremor (ReMi) shear wave technique to geotechnical characterization. In: In Proc. In. Conf. of the Third International Conference on the Application of Geophysical Methodologies and NDT to Transportation and Infrastructure, Florida, pp 8-12

Zhou YG, Chen YM (2007) Laboratory investigation on assessing liquefaction resistance of sandy soils by shear wave velocity. J Geotech Geoenviron 133(8):959-972

Publisher's note Springer Nature remains neutral with regard to jurisdictional claims in published maps and institutional affiliations. 